\title{
The Main Factors, which Predetermine and Limit Weightlifters' Physical Working Capacity and Competitive Activity Effectiveness
}

\author{
Kuznetsov A.S \\ University of management "TISBI" \\ Naberezhnye Chelny, Russia \\ kuznetsov-as@mail.ru
}

\author{
Ibragimov I.N. \\ Tyumen Higher Military-Engineering Command College \\ (military Institute) \\ Tyumen, Russia \\ i-i-n@inbox.ru
}

\author{
Kotkova L.Yu. \\ University of management "TISBI" \\ Naberezhnye Chelny, Russia \\ klumeg@mail.ru
}

\begin{abstract}
The article is about the factors, which predetermine and limit working capacity and competitive activity effectiveness of cadets, who go in for kettlebell lifting. Competitive and training activity of weightlifters can be characterized as the definite motor actions fulfillment in a definite succession during $\mathbf{1 0}$ competitive minutes. Intensiveness of physical load changes depending on the set tempo of motor action fulfillment with constant combination of the act of respiration. In kettlebell lifting, as in many other kinds of sport, the effectiveness criterion of sports training is the final result of an athlete. We can divide the factors of performances effectiveness: on the one hand, it is the training level, on the other hand, it is tactical and psychological readiness.
\end{abstract} activity

Keywords-cadet; kettlebell lifting; factors; competitive

\section{INTRODUCTION}

Physical training of cadets at military higher educational establishments considers different kinds of sport lessons inclusion in terms of the demands realization of physical training and sport instructions in the Armed Forces of the Russian Federation (PTI(physical training instruction)) [9]. Kettlebell lifting plays a special role in the training program of cadets, as a convenient means, which doesn't demand financial investments. It is possible to train in a gym, on the territory of a higher educational establishment or at home. The training lessons of cadets are directed toward taking part in different competitions.

Modern kettlebell lifting is characterized by great tension of competitions increase, which demands not only technical mastery, but also physical-functional and psychological readiness improvement.

The tendency of kettlebell lifting development in cadets of military higher educational establishments demands the factors reconsideration, which predetermine and limit physical working capacity and competitive activity effectiveness.

\section{LITERATURE REVIEW}

Kettlebell lifting is one of strength oriented kinds of sport, which is directed toward athlete's special endurance demonstration. From physiological point of view kettlebell lifting is characterized by dynamic power load fulfillment. During the exercise fulfillment movements alternate in the definite succession: compensatory movements, "Push" exercise, body movement, respiration, movements correspondence, "Burst" and "Respiration" exercises and the elements of movements coordination in a burst and a push.

Different authors consider different sides of training cadets at military higher educational establishments.

A.A. Anasenko (2014) in his work "Training process improvement in kettlebell lifting" considers the ways, which determine the effectiveness increase of training process controlling in kettlebell lifting [1].

M.A. Babintseva (2014) analyzing physical readiness of students-weightlifters, revealed the main factor, which influences competitive effectiveness [2].

M.Yu. Vanyushin, Yu.S. Vanyushin (2011) consider adaptive processes of athletes' cardio-respiratory system to physical load, as a limiting factor of physical working capacity in terms of competitive activity [3].

A.V. Voronkov, I.S. Belyaev, A.Yu. Dorokhin, A.N. Kandabar (2017) offer the methodology of highly-qualified weightlifters physical training. It is based on variety of power endurance development methods using successive and 
balanced, alternating and interval methods, taking into account the periods and stages of training. As the base of an effective methods combination, directed toward physical qualities upbringing among weightlifters, the author offers to create the training programs, which take into account load and rest. In the author's opinion, the base of the methods, which are directed toward physical qualities upbringing, forms different order of loads and rest combination and regulation [4].

E.A.Garanin (2015) considers the methodology effectiveness of training army close fight on the basis of taking into account individual style of sports combat organization, as the base of cadets' competitive activity effectiveness increase. The factor, which limits physical working capacity and cadets' competitive activity, in the opinion of the author, is the training process individualization $[5,6]$.

N.A. Grankin $(2012,2013)$ considers the opportunity to improve cadets training by means of kettlebell lifting. He defines functional readiness as the main factor, which predetermines and limits physical working capacity. In kettlebell lifting, in his opinion, it is important to develop individual respiration rhythm, as the condition for competitive activity effectiveness increase[7,8].

N.N. Sadiev (2014, 2015), studying the questions of students' military-applied physical readiness formation, reveals the problems and ways of this question realization by means of their activity estimation improvement, as one of the factors of cadets' motivation for success. In terms of a difficult military environment the set aim achievement can be expected only from cadets, who are, first of all, motivated to achieve the aim, secondly, who have maximum level of this motivation $[10,11,12,13]$.

Thus, it can be noted that specialists determine different factors, which influence physical working capacity and sports result.

In this connection the aim of this work is to determine and reveal the main factors, which predetermine and limit physical working capacity and competitive activity effectiveness among cadets, who go in for kettlebell lifting.

\section{RESEARCH METHODOLOGY}

We analyzed literature concerning the problem of the research. We held a questioner survey among cadets concerning the importance of the kinds of training in kettlebell lifting and their competence according to the indices, which characterize functional readiness of cadet's organism. We help pedagogical analysis of all sides of training among cadetsweightlifters. Cadets of military-engineering specialty, who go in for kettlebell lifting, took part in the research (Federal State Command Higher Educational Establishment "Tyumen Higher Military-Engineering Command College" (military Institute)"). 21 cadets, who go in for kettlebell lifting and who have competitive experience of different level, took part in a questioner survey.

\section{RESUlTS}

The main ways of training effectiveness improvement among cadets-weightlifter are general and special physical, technical and psychological readiness of cadet-weightlifter and a team in general. Especially important in this case are functional state indices and functional abilities of athletes' organism, which characterize locomotor apparatus, nervousmuscular system and central nervous system state.

In terms of physical training of cadets-weightlifters their morpho-functional status increases and the following physical qualities develop: speed-power qualities and strength; speed capacities and quickness; general and special endurance; coordinating abilities and dexterity; flexibility and activity in joints. Physical qualities development in terms of physical training of cadets-weightlifters is the most important component of functional training. The opportunity training of physical qualities demonstration and motor activities fulfillment help to realize effectively functional potential of each athlete. It should be noted that in kettlebell lifting it is also important to have the ability to switch motor actions, preserving working capacity at a high competitive level.

Technical training in kettlebell lifting includes alternating hands movements, body movements during respiration, in a special rhythm fulfillment. Techniques of a weightlifter are the means of competitive activity realization. That is why the main aim of a weightlifter's technical training is push and snatch techniques improvement and mastering. It is stated that a weightlifter's technique influences all aspects of training. It is an important factor, which limits physical working capacity of a cadet. Tactical activity in kettlebell lifting is considered in terms of operative problems of competitive activity solution, taking into account opponents' abilities. Tactical training can be one of the factors of weightlifters' successful competitive activity if we achieve tactical and technical mastery unity.

An important component can be weightlifters' functional readiness and their morpho-functional characteristics.

It is known that systematic training in power kinds of sport influences morpho-functional status of an athlete. There are considerable changes in nervous-muscular, cardiovascular and respiratory systems.

Psychological training is an important component, which limits weightlifters' successful competitive activity. It is known that in case of equal training level, success is achieved by the athlete, who could use his psychodynamic features of an organism.

The most important component, which limits effective physical working capacity of weightlifters, is taking into account the mechanisms of muscles contraction and relaxation. Weightlifters' physiological activity is directed toward the part of the body movement and different poses holding during muscles relaxation and contraction. Functional characteristics of muscles work can be the factor, which limits physical working capacity and the effectiveness of competitive activity among cadets-weightlifters. 
A questioner survey among cadets-weightlifters helped to estimate the questions concerning the kinds of training in the system of competitive activity according to 5 point system.

First place was given to physical training (56\%). The second place- tactical and technical training (22\%). The third place- functional and psychological training (12\%). $10 \%$ of respondents mentioned as significant all kinds of training (one level of importance).

Thus, it should be noted that the main factor, which limits success of competitive activity among cadetsweightlifters can become a complex many-sided physical training.

It is known that physical working capacity is conditioned by functional state of weightlifters' organism. A questioner survey concerning functional indices helped to define the level of cadets' knowledge concerning this question.

Table I presents the list of the main functional indices and the results of cadets' competence in points.

TABLE I. THE MAIN FUNCTIONAL INDICES, WHICH CHARACTERIZE A PERSON'S HEALTH STATE

\begin{tabular}{|l|l|c|}
\hline № & Functional indices description & $\begin{array}{l}\text { The level of competence in } \\
\text { points }\end{array}$ \\
\hline 1 & Heart rate & $5,0 \pm 0,12$ \\
\hline 2 & Physical working capacity & $3,4 \pm 0,22$ \\
\hline 3 & Maximum oxygen consumption & $2,1 \pm 0,11$ \\
\hline 4 & Blood minute volume & $1,2 \pm 0,11$ \\
\hline 5 & Cardiac stroke volume & $1,4 \pm 0,12$ \\
\hline 6 & Vital capacity & $5,0 \pm 0,13$ \\
\hline 7 & Ruffier's test & $2,0 \pm 0,09$ \\
\hline 8 & Genchi's test & $3,0 \pm 0,12$ \\
\hline 9 & Stange's test & $3,8 \pm 0,14$ \\
\hline 10 & Functional tests & $2,5 \pm 0,14$ \\
\hline
\end{tabular}

It was noted that cadets-weightlifters showed great awareness level concerning functional indices -in the average $3,8 \pm 0,14$ points.

Taking into account that the competition was the final part of the training process, it demonstrated all results of sports training and showed the effectiveness of training. That is why the main factor, which limits physical working capacity during the competitions is an effective stimulation of nervous processes, which control movements and coordinate activity of the whole organism.

That is why the main factor can be preliminary precompetitive training of cadets-weightlifters for an optimal organism reaction formation in terms of competitions. For this purpose it is important to include the factors in to the training process, which provide emotional stimulation (experimental conditions) at different stages of training. The ability to mobilize own abilities, especially functional ones, can be achieved when special conditions are created.

\section{CONCLUSION}

Thus, the most urgent factors, which limit physical working capacity and competitive activity effectiveness among cadets-weightlifters, are the following:
- complex development of important physical qualities taking into account specificity of the kind of sport; solution;

- operative objectives of technical and tactical training

- functional training development and cadet's morphofunctional status control;

- psycho-dynamic features of an organism development;

- physical activity of muscles control;

- the importance of all kinds of training increase;

- competence level increase according to functional indices of an organism.

\section{References}

[1] Anasenko A. A. Training process improvement in kettlebell lifting. Materials of scientific-practical conference. Moscow. 2014, pp. 4-9.

[2] Babintseva M. A. Physical readiness analysis of cadets-weightlifters and its influence on competitive activity effectiveness. Young scientist. 2014, 18, pp. 61-65.

[3] Vanyushin M. Yu., Vanyushin Yu.S. Cardiorespiratory system adaptation to physical loads among athletes of different kinds of sport and age groups. - Kazan : Pechat-Sevis XXI century. 2011, 138.

[4] Voronkov A.V., Belyaev I.S., Dorokhin A.Yu., Kandabar A.N. Methodology of sport training among highly-qualified weightlifters. Modern problems of science and education. 2017, pp. 5. URL: http://science-education.ru/ru/article/view?id=26871.

[5] Garanin E. A.Experimental methodology of training army close fighters taking into account individual style of sports combat organization. Physical culture, sport - science and practice. 2015, 4, pp. 5-11.

[6] Garanin E. A. Physical training of army close fighters taking into account individual style of combat organization. Pedagogicopsychological and medico-biological problems of physical culture and sport. 2014, 3(36), pp. 30-38. DOI:10.14526/08_2014_07.

[7] Grankin N. A. Methodology of military men physical training (exercises with kettle balls), offered in a new physical training instruction (PTI-2009). Collection of scientific-methodical articles, NVVIKU, Kstovo. 2012, pp. 65-70.

[8] Grankin N. A. Endurance upbringing among cadets-weightlifters for actions in extreme conditions. Collection of articles (Experience of teaching listeners and cadets of the Institute) TVIIV. 2013, 13, pp. 7476.

[9] Physical training and sport instruction in the Armed Forces of the Russian Federation (PTI-2009): came into action by the order of the Ministry of Defense of the Russian Federation № 200 April, 21. 2009. URL:

http://voenservice.ru/katalog dokumentov/nastavleniya/nastavlenie-pofizicheskoy-podgotovke-v-voorujennyih-silah-rossiyskoy-federatsii/.

[10] Sadiev N.N., Nagovitsin S.G. Students' military-applied physical readiness formation: problems and the ways of solution. Pedagogicopsychological and medico-biological problems of physical culture and sport. 2014, 1(30), pp. 84-92. DOI: 10.14526/22_2014_22.

[11] Kuznetsova Z.M., Ryabchuk V.A., Labeshchenkov O.V. Theoretical and practical aspects of engineering profile students airborne training individualization. The Russian journal of Physical Education and Sport. 2018,13(2), pp. 160-166. DOI: 10.14526/02_2018_326.

[12] Alexsandr S. Kuznetsov, Richat B. Mubarakzyanov. The Indices interconnection of Greco-roman style wrestlers' functional and technical-tactical readiness. Pedagogico-psychological and medicobiological problems of physical culture and sport. 2017, 12(4), pp. 1925. DOI: 10/14526/04_2017_265

[13] Sadiev N.N. Technology of military-applied physical readiness development among cadets of military-engineering higher educational establishment. Physical culture and sport -science and practice. 2015, 1, pp. 19-25. 